\title{
Surgical Treatment of Benign Fibrous Histiocytoma as a Form of Intraspinal Extradural Tumor at Lumbar Spine
}

\author{
Soo-Beom Kim¹, Jee-Soo Jang ${ }^{2}$, Sang-Ho Lee ${ }^{3}$ \\ 'Department of Orthopaedic Surgery, Seoul Wooridul Hospital, Seoul, Korea \\ ${ }^{2}$ Department of Neurosurgery, Seoul Wooridul Hospital, Seoul, Korea \\ ${ }^{3}$ Department of Neurosurgery, Wooridul Spine Hospital, Seoul, Korea
}

\begin{abstract}
A benign fibrous histiocytoma (BFH) is one of the fibrohistiocytic groups of soft-tissue tumors for which spinal involvement is extremely rare. To the best of our knowledge, most spine-originating BFHs are bone tumors. We report the first case of $\mathrm{BFH}$ occurring in the intraspinal extradural space on the lumbar spine. A 66-year-old female presented with severe claudication symptom. The preoperative magnetic resonance images showed a huge intraspinal, extradural, thecal-sac-compressing soft-tissue tumor that extended along the right L5 root to the neural foramen. The tumor was a relatively wellmarginated, inhomogeneous soft-tissue mass with some fluid-containing cystic portions that were well enhanced by the gadolinium contrast dye. After a total facectectomy, the tumor was removed completely. The patient had a good neurological recovery without complications, and no recurrence was noted at the 6-month follow-up.
\end{abstract}

Key Words: Histiocytoma, Benign fibrous, Soft tissue neoplasms, Lumbar vertebrae

\section{Introduction}

A benign fibrous histiocytoma (BFH) is a member of the fibrohistiocytic groups of soft-tissue tumors. Spinal involvement is extremely rare and most reports of BFH of the spine are of skeletal bone tumors [1-4]. To the best of our knowledge, this is the first report of a soft-tissue BFH that occurred in the intraspinal extradural space along the lumbar spine. We report this case of a rare intraspinal, biopsy-proven BFH that was excised completely by surgery.

\section{Case Report}

A 66-year-old female presented with severe claudication symptoms in both legs that were more prominent on her right side. Her symptoms had been slowly intensifying over the past seven months. The pain did not respond to conservative treatments, such as medication, physical therapy or pain clinic management. According to her prior medical history, she had suffered gouty arthritis and hyperparathyroidism for several years. On the physical examination, the test for straight leg raising was positive on the right side $\left(50^{\circ}\right)$. Her right leg pain radiated along the L5 dermatome. The patient had 4/4 strength of both feet dorsiflexors and big toe dorsiflexors. The laboratory findings revealed leukocytosis $\left(15,200\right.$ cells $\left./ \mathrm{mm}^{3}\right)$, elevated erythrocyte sedimentation rate $(\mathrm{ESR}, 61 \mathrm{~mm} / \mathrm{hr}$ ) and normal C-reactive protein. Her uric acid level was also high $(9.2 \mathrm{mg} / \mathrm{dl})$. The laboratory results suggested manifestations of the active phase of gouty arthritis, but intraspinal abscess formation was also possible. Preoperative magnetic resonance images showed a huge intraspinal, extradural, thecal-sac-compressing soft-

Received Sep 30, 2009; 1st Revised Oct 19, 2009; 2nd Revised Nov 27, 2009; Accepted Nov 28, 2009

Corresponding author: Soo-Beom Kim, MD

Department of Orthopaedic Surgery, Seoul Wooridul Hospital,

676 Gwahae-dong, Gangseo-gu, Seoul 157-822, Korea

Tel: +82-2-2660-7638, Fax: +82-2-2660-7599, E-mail: ourspine@ naver.com 
tissue tumor that extended along the right L5 root to the neural foramen (Fig. 1). The volume of the intraspinal mass was so large that the shape of the thecal sac appeared like a crescent on the T2-weighted axial image. It was decided to remove the mass because the bilateral leg symptoms were believed to be caused from the thecal sac, which was thinly compressed and deviated to the left side. The operation was conducted 10 days after admission due to the hypercalcemia $(12.7 \mathrm{mg} / \mathrm{dl})$ and elevated white blood cell and ESR levels. The tumor was a relatively well-marginated, bilobular, inhomogeneous soft-tissue mass with some fluid-containing cystic portion. A right-side unilateral total facectectomy was performed to remove both the intraspinal and foraminal tumor masses. There was moderate adhesion between the ventral cystic tumor mass and thecal sac (Fig. 2). The sheath of the cystic portion of the tumor was so fragile that it was perforated during the dissection and chocolate-color turbid material gushed out from the mass. Complete removal of the mass was possible without neural damage. The intraspinal cystic mass was connected to the solid portion of the remaining mass overlying the L5 root exit zone. Isthmectomy of the L5 lamina was inevitable because the underlying foraminal portion of the tumor extended to the endpoint of the L5-S1 neural foramen. The cystic and solid portion masses were sent for a biopsy and the collected fluid was cultured to identify any microorganisms. Iatro-
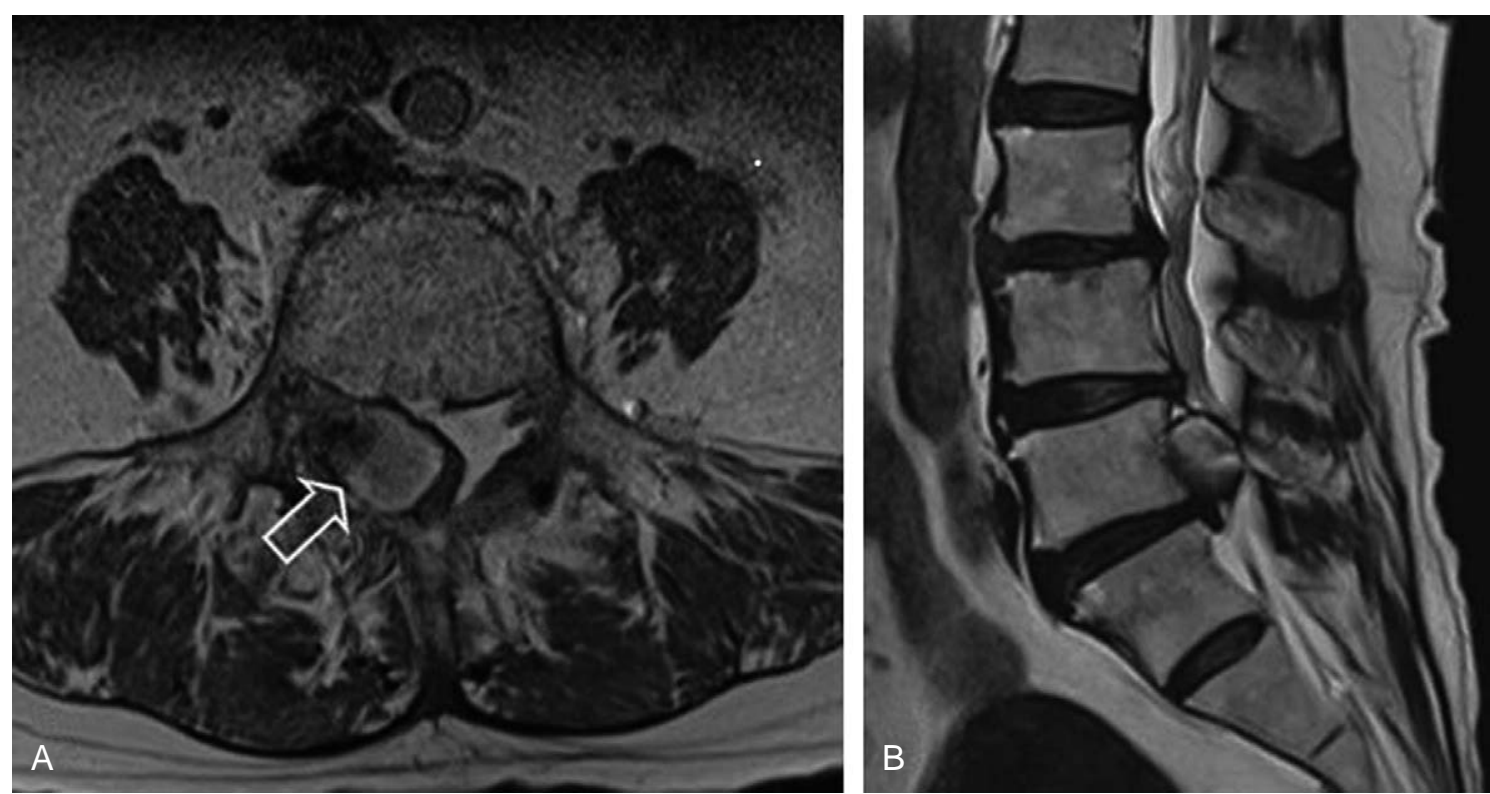

Fig. 1. (A) Initial T2-weighted axial image showing a severely compressed and left-side deviated thecal sac (open white arrow). (B) T2-weighted para-sagittal views showing the ventral located tumor mass extending to the right neural foramen.
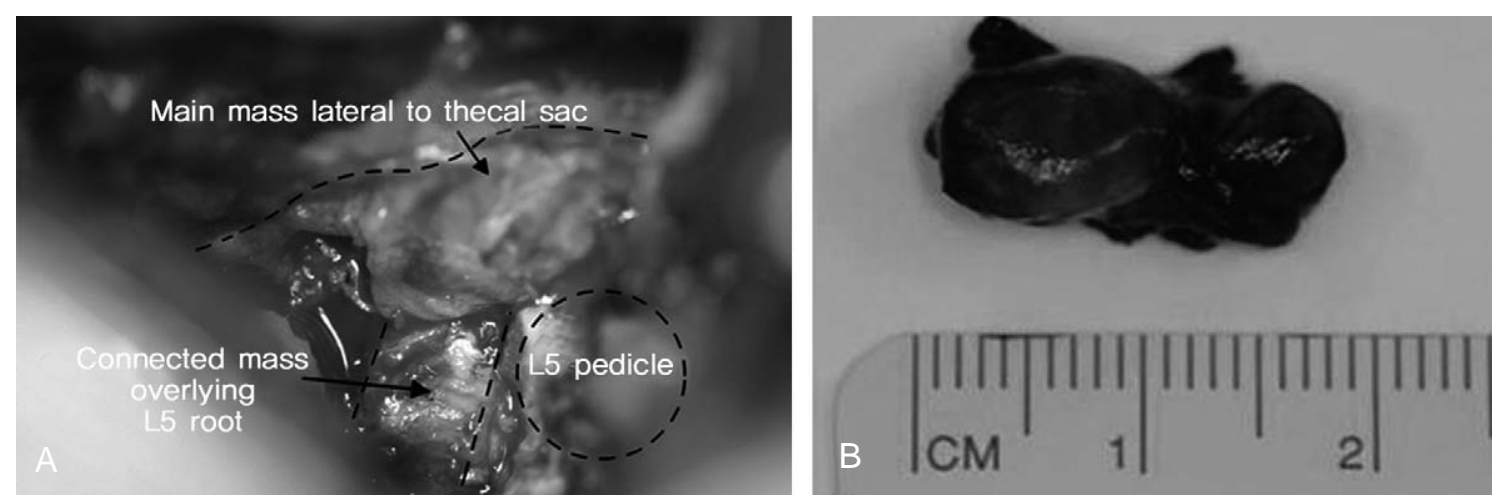

Fig. 2. (A) Intraoperative photograph. Huge yellow to brown cystic tumor mass was located from the ventro-lateral to thecal sac. The tumor mass was connected to the solid portion that overlies the right-side L5 nerve root and ganglion. The total tumor mass size was approximately $3 \times 1 \times 1 \mathrm{~cm}$. (B) Tumor mass removed from neural foramen. 

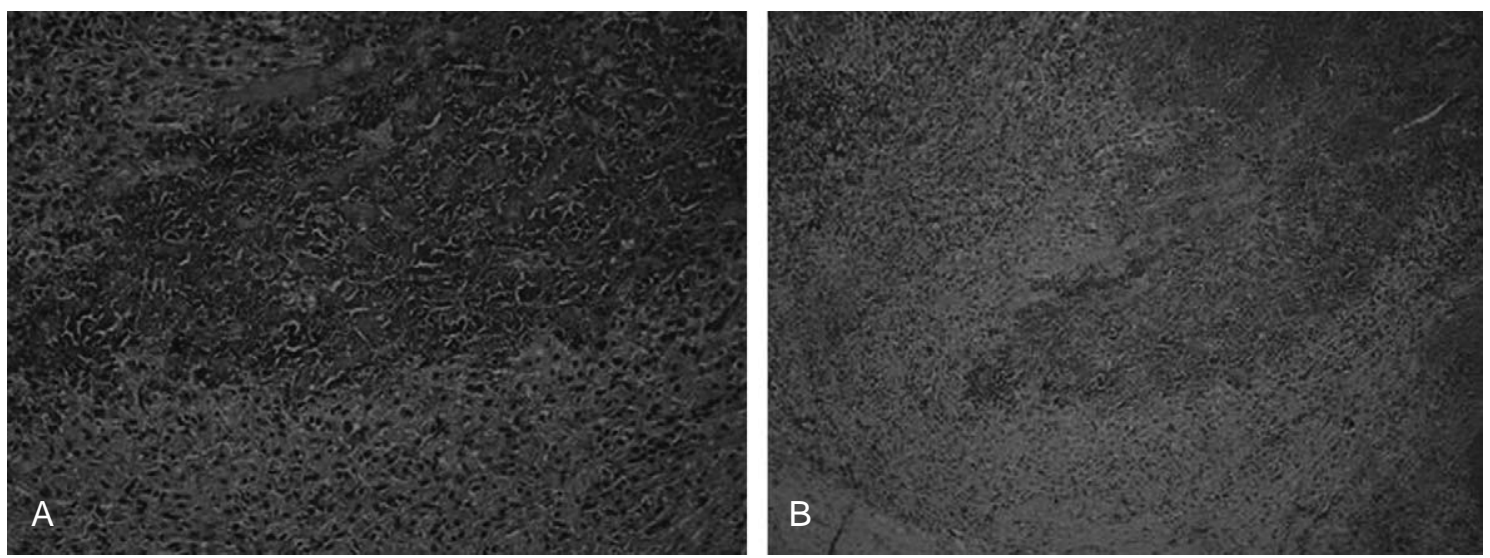

Fig. 3. Histopathologic examination. (A) Characteristic xanthomatous and histiocytic polygonal cells with plump cytoplasm. These cells surround nodules of granuloamorphous debris (hematoxylin and eosin $[H \& E], \times 200)$. (B) Storiform pattern of the fibrous components with multi-focal hemorrhage areas $(\mathrm{H} \& \mathrm{E}, \times 100)$.

genic instability resulting from the unilateral facectectomy and hemilaminectomy was expected. Accordingly, posterior interbody fusion with cage insertion and screw-rod fixation were performed. No microorganisms were cultured. The microscopic view of the removed mass revealed a large amount of fibrohistiocytic cells, plump granular cells showing a storiform arrangement with some vascular ingrowths (Fig. 3). After surgery, her bilateral leg pain improved immediately, and the motor power of ankle dorsiflexion returned to the normal range. There was no recurrence of leg pain or motor weakness at the last six months follow-up after surgery. The follow-up magnetic resonance imaging revealed no residual or recurred mass.

\section{Discussion}

The most prevalent sites of soft-tissue BFHs are the skin and eyeballs, followed by the pharynx, larynx, trachea and lungs. The incidence of BFH in males is approximately double that of females. BFHs originate from the connective tissue, and the tumor is also called an xanthofibroma. Spinal involvement from cervical to sacral vertebra is reported very rarely [2]. The main features of the tumor are abundant xanthomatous cells with foamy, translucent cytoplasm [5]. Histiocytic and xanthomatous cells are localized between the meshes of the fibroblastic network, which sometimes appears in a storiform pattern. The cystic portion of the tumor in this case was considered to be the necrotic portion of the xantho-amorphous portion.

Soft tissue BFHs can be distinguished from other tumors, such as eosinophilic granuloma, non-ossifying fibroma, malignant fibrous histiocytoma or pigmented villonodular synovitis, from the clinical symptoms, age of detection, prevalent site and radiology and histology features $[1,2]$. Old age, non-skeletal tumors, absence of the cytological atypia or high mitotic rate, no pigment or crystal formation, no definite eosinophilia, all indicate a diagnosis of BFH. It is believed that this tumor was not associated with gout, hyperthyroidism or any other infectious conditions of the patient. Treatment of an epidural tumor of a BFH involves complete removal. In our case, the tumor adhered to thecal sac and L5 root. Therefore, the unilateral facet joint was excised inadvertently and interbody fusion was performed to regain stability.

We encountered a rare case of $\mathrm{BFH}$ as an intraspinal epidural lumbar soft-tissue mass. To our knowledge, this is the first report of spinal involvement with a soft-tissue $\mathrm{BFH}$. We report this case along with a brief history and the radiological and histological findings.

\section{REFERENCES}

1. Balasubramanian C, Rajaraman G, Singh CS, Baliga DK. Benign fibrous histiocytoma of the sacrum: diagnostic difficulties facing this rare bone tumor. Pediatr Neurosurg 2005;41:253-7.

2. Demiralp B, Kose O, Oguz E, Sanal T, Ozcan A, Sehirlioglu A. Benign fibrous histiocytoma of the lumbar vertebrae. Skeletal Radiol 2009;38:187-91.

3. Hoeffel JC, Boman-Ferrand F, Tachet F, Lascombes P, Czorny A, Bernard C. So-called benign fibrous histiocytoma: report of a case. J Pediatr Surg 1992;27:672-4.

4. Kuruvath S, O'Donovan DG, Aspoas AR, David KM. Benign fibrous histiocytoma of the thoracic spine: case 
report and review of the literature. J Neurosurg Spine 2006;4:260-4.

5. Roessner A, Immenkamp M, Weidner A, Hobik HP,
Grundmann E. Benign fibrous histiocytoma of bone: lightand electron-microscopic observations. J Cancer Res Clin Oncol 1981;101:191-202. 